\title{
Mating Behavior of Wild Melon Flies, Dacus cucurbitae CoQuilletT (Diptera: Tephritidae) in a Field Cage: Courtship Behavior
}

\author{
Hiroyuki KuBA ${ }^{1}$ and Juro KoyAma ${ }^{2}$ \\ Okinawa Prefectural Agricultural Experiment Station, Naha, Okinawa 903, Japan
}

(Received February 9, 1985)

\begin{abstract}
The mating behavior of wild melon flies, Dacus cucurbitae Coquillett, released on a fieldcaged non-host tree (coral tree) was observed. When the light intensity decreased toward dusk, males stationed themselves on the bottom surface of leaves and formed a lek. In the lek, males were stationary, then engaged in wing vibration and released a sex pheromone. Each male individually occupied a leaf as a territory and defended it against other males which approached. When the males began to release pheromone, a female approached a chosen male from the front, and the male attempted copulation.
\end{abstract}

\section{INTRODUCTION}

Recent field cage studies have provided information on lek formation and territoriality in several tephritid species: Ceratitis capitata (Wiedemann) (Prokopy and Hendrichs, 1979); Anastrepha suspensa (Loew) (Dodson, 1982); A. ludens (L.) and A. oblicua (M.) (Aluja et al., 1982); A. fraterculus (Wiedemann) (Morgante et al., 1983). In our previous observations on the mating behavior of wild melon flies, Dacus cucurbitae CoQuilletr, conducted in a field cage, we found that males emitted sex pheromone on tree leaves and receptive females were attracted to and copulated with these males on the leaves. These observations strongly suggested the existence of lek formation on tree leaves by the males (KuBA et al., 1984).

However, there were few observations of successful copulation in the previous study. The present report describes the results of subsequent detailed observations including descriptions of courtship behavior patterns of males and females.

\section{MATERIALS AND METHODS}

Insects and field cage. The conditions of flies and the field cage used for the observations were similar to those in the previous report except for age of adults and the existence of host fruit. Here, the age of adult flies was 31-41 days old, and we did not distribute fruit on the tree because no matings occurred on fruit (KuBA et al., 1984).

1 Present address: Fruit-fly Eradication Project Office, Okinawa Prefectural Government, Maji, Naha, Okinawa 902, Japan

2 Present address: Kyushu National Agricultural Experiment Station, Chikugo, Fukuoka 833, Japan 
Observation of flies. Observations were conducted on 20, 22, 28, 29 and 30, Oct. 1980. We released 30 males and 30 females each observation day on a field-caged coral tree 150 min before dusk (dusk $=0$ lux time). All of the flies from a previous observation day were removed from the cage prior to the next observation day. As the flies almost always mate only on the tree, we observed only the flies on the tree. Observations began $15 \mathrm{~min}$ after fly release and ended at dusk, when we could no longer observe flies and all flies became stationary. Observations were conducted by a pair of observers; one observer followed only males and the other followed only females. Observers selected a fly to observe at random and observed and recorded the actions of the fly for as long as it remained in view up to a maximum of $5 \mathrm{~min}$. When the observer lost sight of the selected fly or it successfully copulated, the observation period ended and another fly was selected for observation. We recorded the following actions of observed flies: (1) movement (stationary, walking, flying); (2) encounters between flies; (3) direction of the counterpart (i.e. the fly interesting with the observed fly) relative to the object (i.e. the observed fly) just prior to encounter (front, rear, other) (Fig. 1) ; (4) copulation attempts; (5) position of the object fly relative to a counterpart when a copulatory attempt was made by a male (front, rear, other) (Fig. 2); (6) escape from the counterpart; (7) copulation attempt performed by counterpart; (8) escape of the counterpart from the object fly; (9) wing vibration of object male; $(10)$ wing vibration

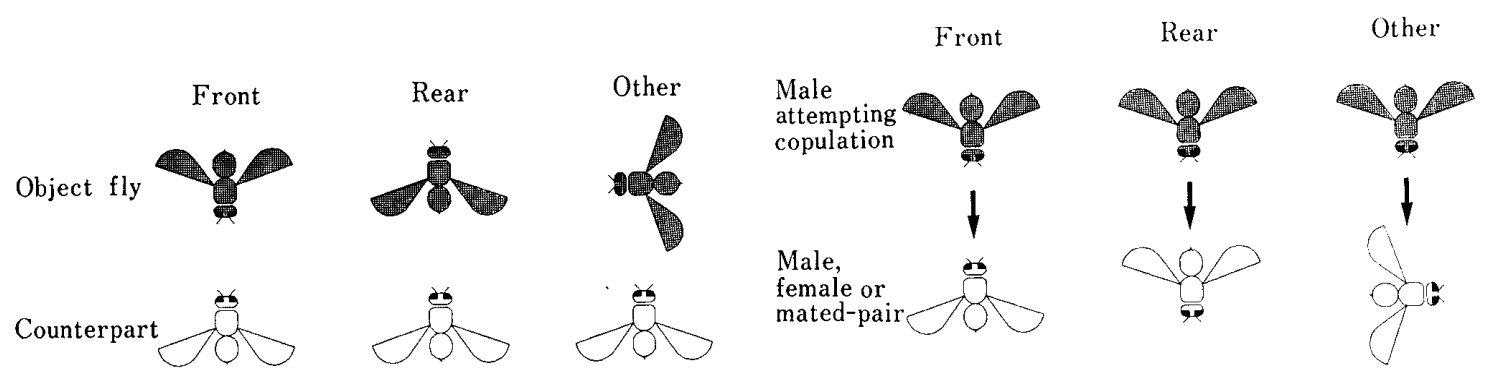

Fig. 1. Diagram of direction of counterpart (hollow) to object fly (shaded) when encounters occurred.

Fig. 2. Diagram of position of male (shaded) which attempted copulation relative to male, female or mated pair (hollow).

Table 1. Records of observed activities of object males and counterparts when encounters

\begin{tabular}{ccccccc}
$\begin{array}{c}\text { Object: } \\
\text { counterpart }\end{array}$ & $\begin{array}{c}\text { Copulation } \\
\text { attempt of } \\
\text { object male }\end{array}$ & $\begin{array}{c}\text { No. } \\
\text { observed }\end{array}$ & $\begin{array}{c}\text { Stationary } \\
\text { of object males }(\%)\end{array}$ & Walk & Fly & $\begin{array}{c}\text { Object engaged } \\
\text { in wing } \\
\text { vibration } \\
(\%)\end{array}$ \\
\hline Male: male & Yes & 14 & 100 & 29 & 21 & 100 \\
Male: female & No & 47 & 85 & 40 & 32 & 55 \\
Male: & Yes & 13 & 85 & 8 & 23 & 100 \\
pated- & No & 28 & 82 & 39 & 11 & 64 \\
Yes & No & 14 & 71 & 50 & 79 & 86
\end{tabular}

a Total of percentages exceeded $100 \%$ because some flies performed more than one type of activity

b See Fig. 1.

c See Fig. 2. 
of counterpart male. Here, according to PROKopy et al. (1971), we define an encounter as a meeting of flies in which there was (to the observer) discernible recognition by each fly of the other fly's presence, as evidenced by the flies' visual attentiveness or movement. A copulation attempt is defined as the leap of a fly onto another fly, and a successful copulation as the apparent intromission of the aedeagus into the ovipositor.

\section{RESULTS}

\section{Encounters and attempted copulations of males}

Out of a total of 126 encounters of males observed during the observation of males, 61 were male:male encounters, 41 male:female encounters, and 24 male:mated-pair encounters. Table 1 shows a record of observed activities of object males and counterparts with (yes) or without (no) copulation attempts.

In 14 of the 61 male:male encounters, all object flies attempted copulation from the front. These object males were almost all stationary and all engaged in wing vibration, while $57 \%$ of the counterparts engaged in wing vibration. When encounters occurred, almost all counterparts approached object flies from the front $(93 \%)$.

In 47 of the 61 male:male encounters, object males did not attempt copulation. These object males more frequently walked or flew compared with males which attempted copulation, and few of the object males engaged in wing vibration $(55 \%)$. In these cases, counterparts approached object flies not only from the front $(60 \%)$ but also from the rear or from other directions $(39 \%)$.

Table 2 shows the relationship between wing vibration and escape of object flies from conterpart males when encounters occurred. Out of 61 observations of males engaged in wing vibration, only 9 object flies escaped from counterparts. In cases where no wing vibration occurred, the probability of object fly escaping was ca. 0.5 $(32 / 61)$. As sexual activities increased toward dusk, each male took up his residence on single leaf, engaged in wing vibration, and by various defensive behaviors established territories against all intruders other than conspecific females. Sometimes the defense occurred through head batting or violent wrestling and occasionally it occurred through copulation attempts. We could not discriminate whether these copulatory attempts

occurred on tree leaves

\begin{tabular}{|c|c|c|c|c|c|c|c|c|}
\hline \multicolumn{4}{|c|}{$\begin{array}{l}\text { Direction of counterpart } \mathrm{t}^{\mathrm{b}} \text { relative } \\
\text { to object males when encounter } \\
\text { occurred }(\%)\end{array}$} & \multicolumn{3}{|c|}{$\begin{array}{c}\text { Position of object males }{ }^{\mathrm{c}} \text { relative } \\
\text { to counterparts when copulation } \\
\text { was attempted }(\%)\end{array}$} & \multirow{2}{*}{$\begin{array}{l}\text { Counterpart } \\
\text { engaged in } \\
\text { wing } \\
\text { vibration }(\%)\end{array}$} & \multirow{2}{*}{$\begin{array}{l}\text { Copulation } \\
\text { attempt of } \\
\text { counterpart } \\
(\%)\end{array}$} \\
\hline Front & Rear & Other & Unknown & Front & Rear & Other & & \\
\hline 93 & 0 & 0 & 7 & 100 & 0 & 0 & 57 & 0 \\
\hline 60 & 28 & 11 & 0 & - & - & - & 28 & 6 \\
\hline 100 & 0 & 0 & 0 & 69 & 15 & 15 & - & - \\
\hline 89 & 4 & 7 & 0 & - & - & - & - & - \\
\hline 93 & 0 & 0 & 7 & 57 & 14 & 29 & - & - \\
\hline 90 & 0 & 0 & 10 & - & - & - & - & - \\
\hline
\end{tabular}


Table 2. Relationship of engagement in wing vibration and escape (combined data when object fly escaped from counterpart and counterpart escaped from object fly)

\begin{tabular}{llcc}
\hline & & \multicolumn{2}{c}{ Wing vibration } \\
\cline { 3 - 4 } & & Yes & No \\
\hline Escape & Yes & 9 & 29 \\
& No & 52 & 32 \\
& Total & 61 & 61 \\
\hline
\end{tabular}

occurred because males were unable to distinguish between the sexes or were actually a form of male territorial defense. Nevertheless, males which attempted copulation succeeded in excluding male intruders.

In 13 of the 41 male:female encounters, males attempted copulation (Table 1). All these males also engaged in wing vibration. Counterpart females only approached object males from the front. In $69 \%$ of these 13 cases, males attempted copulation from a frontal position relative to females. But some of the females changed their direction, subsequently, and some of copulation attempt occurred from rear $(15 \%)$ or other $(15 \%)$ positions. In 28 cases without copulation attempts, $64 \%$ of males engaged in wing vibration. Counterpart females usually approached object males from the front $(89 \%)$ and in a few cases from the rear or other directions $(11 \%)$.

As light intensity decreased toward dusk, the number of mated pairs increased. Out of 24 male:mated-pair encounters, 14 males attempted copulation. However, courtship behavior was different from the cases of male:famale encounters. When male:mated-pair encounter occurred, the direction of mated pairs relative to the object male were almost frontal $(93 \%)$. However, copulation attempts of the object male from a frontal position were less frequent $(57 \%)$, because male actively walked or flew around the mated-pairs which were relatively stationary. Furthermore, the proportion of males engaged in wing vibration decreased slightly $(86 \%)$.

In 10 of the 24 male:mated-pair encounters, males which did not attempt copulation were infrequently stationary $(30 \%)$ but walked $(70 \%)$ or flew $(50 \%)$ more actively, all of the males engaged in wing vibration.

\section{Encounters of females}

Out of a total of 70 encounters of females to other individuals seen during the female observations, the majority were female:male encounters (57) (Table 3).

In 24 of the 57 female:male encounters, copulation attempts by the male were observed. In these cases, the object females were more actively walking or flying than the males which attempted copulation (see Table 1). Out of the 24 cases of attempted copulation, 75\% achieved successful copulation. Counterpart males approached object famales primarily from the front $(83 \%)$. All counterpart males engaged in wing vibration, similar to the pattern of male:female encounters (Table 1).

In 33 of 57 female:male encounters, copulation attempts were not observed. In these cases, females were more stationary $(73 \%)$ than in cases in which copulations were attempted. Furthermore, only half of the counterpart males engaged in wing vibration, and the directions of males to females were different from other types of encounter, i.e, the proportion of rear and other directions was high $(51 \%)$. 

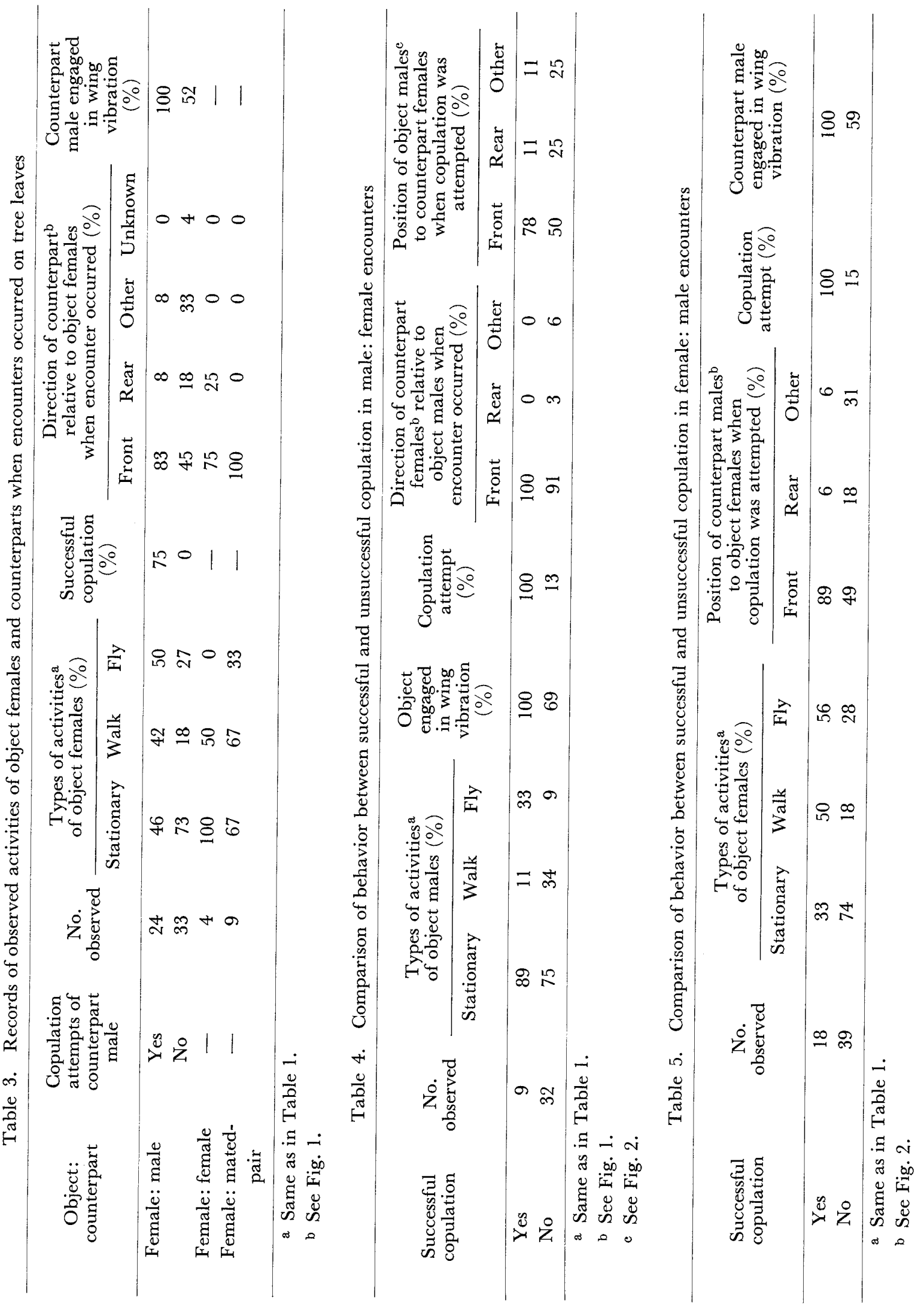
We observed only 4 instances of female:female encounters. In the 9 female: mated-pair encounters observed, most of the females were actively walking and flying and approached the mated pair from the front. These females moved around the mated pair and put their head or ovipositor against the mated pair.

\section{Copulation}

Out of the 41 male:female encounters observed when a male was the object fly, 9 resulted in successful copulation and 32 were unsuccessful (Table 4). In successful cases, males were mostly stationary, but all of them engaged in wing vibration and attempted copulation. In unsuccessful cases, wing vibration of males was infrequent $(69 \%)$ and only $13 \%$ of the males attempted copulation. When males attempted copulation, the position of males relative to females was almost always frontal in successful cases $(78 \%$ ), while in unsuccessful cases the frequency of the frontal position was lower $(50 \%)$. When encounters occurred, most of the females approached males from a frontal direction whether copulation were successful $(100 \%)$ or unsuccessful $(91 \%)$.

Out of the 57 female:male encounters observed when a female was the object fly, 18 resulted in successful copulation and 39 were unsuccessful (Table 5). In successful cases, the females actively moved, while in unsuccessful cases, the proportion of stationary female was high $(74 \%)$. The proportion of males engaged in wing vibration in successful cases was $100 \%$, while in unsuccessful cases it was 59\%. Direction of approach of males in successful cases was almost always frontal $(89 \%)$, while frontal approaches were less common $(49 \%)$ in unsuccessful cases. These outcomes were similar to those observed in male:female encounters (Table 4).

\section{DISCUSSION}

The observational findings of this study on courtship behavior of wild melon flies are summarized as follows. A female arrives at a leaf where a male engaging in wing vibration and emitting sex-pheromone (KuBA et al., 1984), and she approaches the male by short flights and/or walking. At this time, a male:female encounter occurs, and the orientation of the male and the female in relation to each other is usually frontal (i.e. face to face). When the female approaches the male within a distance of $2-3 \mathrm{~cm}$, the male begins to approach the female and attempts copulation from the front. Sometimes, the male attempts copulation from another direction, however, the probability of successful copulation is lower than in the frontal position.

Male:male encounters were observed frequently (31\% of encounters observed). We think that these frequent male:male encounters are the result of lek formation of males. In regard to territoriality, a male which is stationary and engages in wing vibration excludes other males that intrude on the leaf already occupied by the male. But a male dose not necessarily defend a specific leaf because the male will sometimes change his position in the lek.

As pointed out in our previous report (KuBA et al., 1984), lek formation, territoriality and courtship behaviors of the melon fly are similar to behaviors exhibited by fieldcaged Dacus tryoni in studies by Tychsen (1977). However, the melon fly does not engage in flying swarms (KubA et al., 1984), as observed in D. tryoni, before formation of a settled swarm (=lek). Individual melon fly males also occupied a larger territory 
than individual $D$. tryoni which are about $2 \mathrm{~cm}$ in size compared with ca. $10 \mathrm{~cm}$ (mean size of a leaf) for melon flies.

Very few female:female encounters ( $2 \%$ of encounters observed) were observed; we think these encounters were accidental rather than being due to mutual attractiveness. This situation is similar to that of Anastrepha fraterculus (MORGANTE et al., 1983).

When male:mated-pair encounters and male:male or male:female encounters are compared, we see that mobilities of males are different (Table 1). Originally, males are stationary at low light intensity and wait for females (waiting behavior), but as the number of mated pairs increases, males which fail to mate begin to move and search for responsive females (searching behavior). These males engaged in wing vibration during searching. With respect to female:mated-pair encounters, it is suggested that sex pheromone remains around mated pairs for a short time after they have mated because females approach mated pairs and behave as if the mated pairs were males.

Suzuki and Koyama (1980) and Kuba and Koyama (1982) indicated that massreared strains of the melon fly initiate sexual activity earlier in the day than the wild strain. Dodson (1982) stated that flies from a laboratory colony of Anastrepha suspensa reared for more than 20 years showed different courtship behavior from wild flies. Lab flies showed none of the aggressive behavior which was observed among wild males. Homosexual behavior, which was not observed among wild males in this species, occurred among lab males. While wild flies mated only on the abaxial sides of leaves, lab flies mated on the cage and on other available areas. From the viewpoint of the sterile insect technique, such differences in mating behavior could influence successful mating between mass-reared, released flies and wild flies. Thus, lek formation and territoriality in the mass-reared strain of the melon fly should be studied and compared with the behaviors of the wild flies reported here.

\section{ACKNOWLEDGEMENTS}

We are thankful to the staffs of the Fruit Flies Laboratory, Okinawa Prefectural Agricultural Experiment Station for their valuable suggestions. We are also indebted to S. B. Opp and R. J. Prokopy for comments on an earlier version of the manuscript.

\section{REFERENCES}

Aluja, M., J. Hendrichs and M. Cabrera (1982) Behavior and interactions between Anastrepha ludens (L.) and A. oblicua (M.) on a field caged mango tree I. Lekking behavior and male territoriality. CEC IOBC Symp. Athens, pp. 122-133.

Donson, G. (1982) Mating and territoriality in wild Anastrepha suspensa (Diptera: Tephritidae) in field cages. J. Georgia Entomol. Soc. 17: 189-200.

Kuba, H. and J. Koyama (1982) Mating behavior of the melon fly, Dacus cucurbitae Coquillett (Diptera: Tephritidae): Comparative studies of one wild and two laboratory strains. Appl. Ent. Zool. 17: 559568.

Kuba, H., J. Koyama and R. J. Prokopy (1984) Mating behavior of wild melon flies, Dacus cucurbitae Coquillett (Diptera: Tephritidae) in a field cage: Distribution and behavior of flies. Appl. Ent. Zool. 19 : 367-373.

Morgante, J. S., A. Malavasi and R. J. Prokopy (1983) Mating behavior of wild Anastrepha fraterculus (Diptera: Tephritidae) on a caged host tree. Fla. Entomol. 66: 234-241. 
Prokopy, R. J. and J. Hendrichs (1979) Mating behavior of Ceratitis capitata on a field-caged host tree. Ann. Entomol. Soc. Am. 72: 642-648.

Prokopy, R. J., E. W. Bennett and G. L. Bush (1971) Mating behavior in Rhagoletis pomonella (Diptera: Tephritidae) I. Site of assembly. Can. Ent. 103: 1405-1409.

Suzukr, Y. and J. Koyama (1980) Temporal aspects of mating behavior of the melon fly, Dacus cucurbitae Coquillett (Diptera: Tephritidae): A comparison between laboratory and wild strains. Appl. Ent. Zool. 15: 215-224.

Tychsen, P. H. (1977) Mating behavior of the Queensland fruit fly, Dacus tryoni (Diptera: Tephritidae), in field cages. J. Aust. Entomol. Soc. 16: 459-465. 